\title{
Immunoreactive determinants of CA 125 in women with endometriosis
}

\author{
O A MOJIMINIYI, M E BRAMWELL, $\dagger$ S H KENNEDY, * B J SHEPSTONE, \\ S M HUMM, $\dagger$ D H BARLOW* \\ From the University Department of Radiology, Radcliffe Infirmary, Oxford, the *Nuffield Department of \\ Obstetrics and Gynaecology, and the †Sir William Dunn School of Pathology, University of Oxford
}

SUMMARY Among 10 patients with endometriosis CA 125 was increased ( $>35 \mathrm{U} / \mathrm{ml}$ ) in endometriotic cyst fluid in all the patients, but only two had increased serum concentrations. Gel electrophoresis of serum, endometriotic cyst fluid, and endometriotic tissue resolved the CA 125 immunoreactive fragments from the three sources into bands of similar electrophoretic mobilities. Electrophoresis under reducing and non-reducing conditions showed immunoreactive fragments of apparent masses of 55000 and 140000 daltons, respectively. Analysis under reducing conditions did not result in loss of activity. CA 125 antigen is thought to be a high molecular weight glycoprotein complex. As far as is known, this is the first report describing lower molecular weight immunoreactive determinants of CA 125.

CA 125 is an antigen recognised by the monoclonal antibody OC 125 obtained through somatic hybridisation of splenic cells of mice immunised with a cell line of OVCA 433 ovarian cancer. ${ }^{1}$ The antigen is expressed by most common epithelial ovarian carcinomas. In non-malignant tissue the antigen is frequently expressed in benign ovarian tumours of mucinous and non-mucinous origin. ${ }^{2-5}$ as well as in endometriosis. ${ }^{6-9}$ The presence of the antigen has also been shown in human milk, ${ }^{10}$ amniotic fluid, ${ }^{11}$ cervical mucus, ${ }^{12}$ central airway and lung tissue ${ }^{13}$ and seminal plasma. ${ }^{14}$ These findings suggest that CA 125 may be a secretory product of many normal human epithelia.

The CA 125 determinant has been reported to be associated with a mucin like high molecular weight glycoprotein complex, ${ }^{1015}$ but several epitopes of the antigen have been identified, ${ }^{16}{ }^{17}$ and the recognition of a different epitope by a monoclonal antibody raised against lung cancer cells ${ }^{16}$ suggests that different epitopes may be expressed in the various conditions with increased tissue expression of the antigen. After our previous report on the successful immunoscintigraphic localisation of areas of endometriosis ${ }^{18}$ this study was set up to characterise the epitope bound by OC 125 in endometriosis.

\section{Material and methods}

Samples of serum and endometriotic cyst fluid were

Accepted for publication 11 July 1989 obtained from 10 women undergoing oocyte retrieval for in vitro fertilisation. Fresh frozen tissue histologically confirmed as endometriosis was obtained from the Nuffield Department of Obstetrics and Gynaecology, Oxford, and a melanoma cell line was obtained from the Sir William Dunn School of Pathology, Oxford. The monoclonal antibody OC 125 was obtained from CIS (UK, Ltd).

The samples were analysed by sodium dodecyl sulphate polyacrylamide gel electrophoresis (SDSPAGE) under reducing (with DTT and heating) and non-reducing (without DTT and without heating) conditions. In the first run $10 \mu \mathrm{l}$ of sample fluid and 40 $\mu \mathrm{l}$ of solubilising buffer ( $2 \%$ SDS, TRIS- $\mathrm{HCl} 10 \mathrm{mM}$, $\mathrm{pH} 8 \cdot 0,0 \cdot 1 \mathrm{M}$ DTT and $10 \%$ glycerol) was boiled for two minutes before running on SDS-PAGE. Tissues were finely minced, rinsed in distilled water, and extracted with $0.2 \%$ sodium deoxycholate in TRIS$\mathrm{HCl}, 10 \mathrm{mM}, \mathrm{pH} 8.0$, for five minutes at $20^{\circ} \mathrm{C}$. Insoluble material was spun off in a microfuge at 9000 $g$ for two minutes and $25 \mu \mathrm{l}$ of the supernatant taken for analysis on SDS-PAGE. In the second (non-reducing) run the samples were applied in solubilising buffer not containing DTT and without boiling.

SDS-PAGE was performed as previously described $^{1920}$ in 4-12.5\% gradient slab gels using the LKB vertical gel apparatus run at $4 \mathrm{~V} \mathrm{~cm}-1$ for 16 hours. The molecular weight standards used were myosin (200 kilodaltons), b-galactosidase (116 kilodaltons), phosphorylase ( 94 kilodaltons), bovine albumin (67 kilodaltons), bovine albumin (67 kilodaltons) and ovalbumin (43 kilodaltons). 


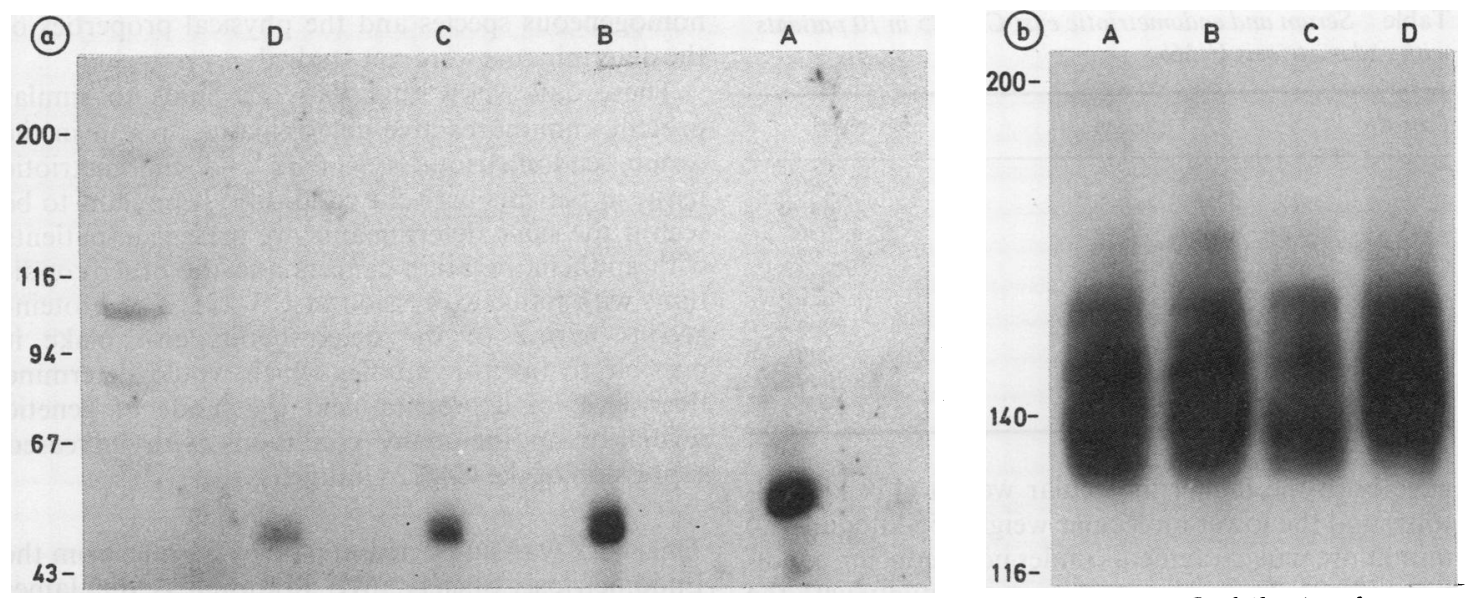

Fig 1 Conventional SDS-PAGE (4-12.5\% gradient) of endometriotic tissue (a), endometriotic cysts fluid ( $b, c)$ and serum (d) from patients with endometriosis under reducing ( $1 a$ ) and non-reducing conditions (1b). Approximate mobilities of molecular weight standards are indicated by arrows or arrow heads. The molecular weight standards used were myosin (200 kilodaltons), b-galactosidase (116 kilodaltons), phosphorylase (94 kilodaltons), bovine albumin (67 kilodaltons) and ovalbumin (43 kilodaltons). Other indicated mobilities are approximate.

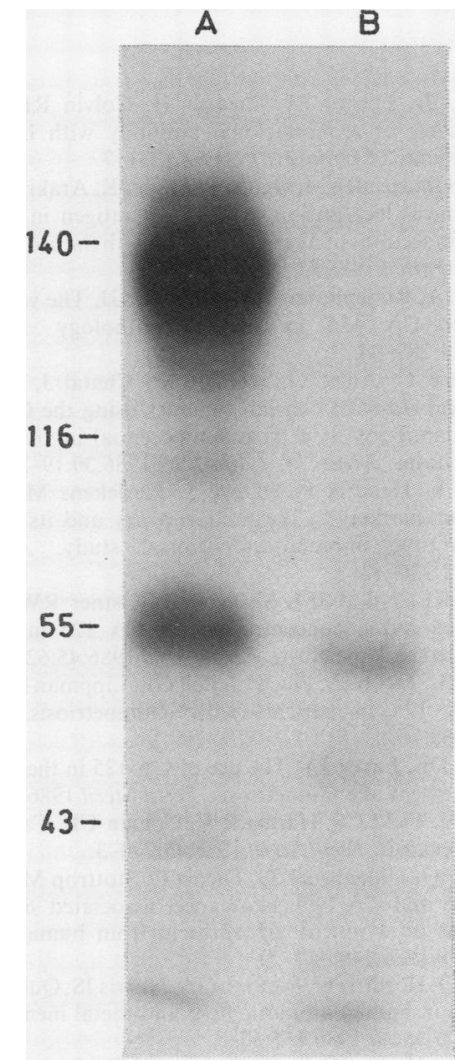

Fig 2 SDS-PAGE of endometriotic cyst fuid from case 9 under non-reducing (lane A) and reducing (lane B) conditions.
The SDS-PAGE gels were subjected to electrophoretic transfer in TRIS-glycine buffer $(25 \mathrm{mM}$ and $192 \mathrm{mM}$, respectively), pH 8.3, containing $20 \%$ methanol, using the Transblot system (Biorad Laboratories, Richmond, California). Proteins and glycoproteins were transferred to nitrocellulose membrane filters (Schlecher and Schuell, GmbH, Dassel, West Germany), washed in PBS containing 0.4 M $\mathrm{NaCl}$ and $0.2 \%$ Tween 20 (PNT), and blocked in $1 \%$ bovine serum albumin in PNT for 30 minutes. After rinsing in distilled water the membrane was incubated in OC 125 at a 1 in 20 dilution in PNT for 30 minutes. After being washed three to four times in PNT buffer the membrane was incubated in ${ }^{125}$ I-labelled antimouse IgG for 30 minutes. Excess radioactivity was washed off with $0.1 \% \mathrm{w} / \mathrm{v}$ SDS in PBS. After staining with amido black (Sebia) the membrane was dried and exposed to $x$-ray film (Fuji Photo Film Company, Japan) at $-70^{\circ} \mathrm{C}$ for 24 hours.

The serum samples and endometriotic cysts fluid were analysed for CA 125 content by an immunoradiometric assay according to the manufacturer's instructions (CIS, UK).

\section{Results}

When the samples were subjected to SDS-PAGE under reducing conditions followed by immunoblotting, OC 125 was reactive with a band of about 55 kilodaltons in all the samples (fig la). Under nonreducing conditions and without heating, the immunoreactive fragments were about 140 kilodaltons. The endometriotic cyst fluid from case 9 (table) 
Table Serum and endometriotic cyst CA-125 in 10 patients with endometriosis $U / M I$

\begin{tabular}{lrr}
\hline Case No & Serum & \multicolumn{1}{c}{ Cyst } \\
\hline 1 & 12 & 440 \\
2 & 94 & 146 \\
3 & 8 & 956 \\
4 & 10 & 92 \\
5 & 12 & 820 \\
6 & 18 & 796 \\
7 & 18 & 300 \\
8 & 18 & 296 \\
9 & 40 & $>1000$ \\
10 & 12 & $>1000$ \\
\hline
\end{tabular}

gave both the higher molecular weight (140 kilodaltons) and the lower molecular weight (55 kilodaltons) immunoreactive fragments under non-reducing conditions (fig 2). There was no immunoreactivity with the serum of case 3 under reducing and non-reducing conditions, presumably because of the low $(8 \mathrm{U} / \mathrm{ml})$ CA 125 content. In cases 6 and 7 there was immunoreactivity with the sera only under non-reducing conditions. There was no immunoreactivity with the melanoma cell line. Immunoreactive species of 200 kilodaltons or more were not obtained in any of the samples. Despite the highly increased CA 125 content of all the endometriotic cysts only two patients showed increased serum concentrations (table).

\section{Discussion}

CA 125 antigen is defined by the monoclonal antibody OC 125 which identifies a conformational epitope to which both saccharides and protein contribute. CAMOV2, an oligosaccharide, is only occasionally expressed on the same molecule as CA $125 .{ }^{17}$ Various reports suggest that CA 125 is expressed independently of both the milk mucin family antigen ${ }^{21}$ and the CA 19.9 antigen. ${ }^{22}$

Studies on the antigenic nature of CA 125 show that it is a glycoprotein with a molecular weight in excess of $200000 .^{15}$ Davis et al also obtained similar data and suggested that the actual protein which expresses the antigenic determinant may be of a lower molecular weight. ${ }^{22}$ Our results show clearly that OC 125 binds to lower molecular weight determinants in endometriosis. Heating and analysis of the samples under reducing conditions did not inactivate the CA 125 antigen as previously suggested ${ }^{22}$ but produced lower molecular weight immunoreactive fragments. The CA 125 antigen seems to consist of, at least in part, protein determinants of 55 kilodaltons and 140 kilodaltons in endometriosis. The failure to obtain the high molecular weight immunoreactive species is difficult to explain, but the nature of the CA 125 determinant in endometriosis may be different. Our studies, however, did not attempt to purify and study homogeneous species and the physical properties of the determinants were not studied.

These data show that OC 125 binds to similar protein immunoreactive determinants present in the serum, endometriotic cyst fluid and endometriotic tissue in patients with the condition. It remains to be seen if the same determinants are present in patients with epithelial ovarian cancers and the other conditions with tissue expression of CA 125 . The proteinaceous nature of the determinants also make it possible to institute studies which would determine their level of expression and the mode of genetic regulation in the many conditions with increased expression of the CA 125 antigen.

This work was supported in part by a grant from the Endometriosis Society. ME Bramwell is the James Hanson Research Fellow of the Cancer Research Campaign. Most of the work was done while OA Mojiminiyi was on the International Atomic Energy Agency Fellowship. He is currently a Siemens Scholar.

\section{References}

1 Bast RC Jr, Feeney M, Lazarus H, Colvin RB, Knapp RC Reactivity of a monoclonal antibody with human ovarian carcinoma. J Clin Invest 1981;68:1331-7.

2 Shishi J, Ghazizadeh M, Oguro T, Aihara K, Araki T. Immunohistochemical localisation of CA 125 antigen in formalin-fixed paraffin sections of ovarian tumours with the use of pronase. $\mathrm{Am}$ J Clin Pathol 1986;85:595-8.

3 Koelma IA, Rodenburgh NM, Fleuren GJ. The value of tumour marker CA 125 in surgical pathology. Histopathology 1987;11:287-94.

4 Mainguene C, Aillet G, Kremer M, Chatal J. Immunohistochemical study of ovarian tumours using the OC 125 monoclonal antibody as a basis for potential in-vivo and in-vitro applications. J Nucl Med Allied Sci 1986;30:19-22.

5 Nouwen E, Hendrix P, Dauwe S, Eerdekens M, De Broe M. Tumour markers in the human ovary and its neoplasms. A comparative immunohistochemical study. Am J Pathol 1987:12:230-42.

6 Barbieri RL, Niloff JM, Shcaetzl E, Kistner RW, Knapp RC. Elevated serum concentrations of CA 125 in patients with advanced endometriosis. Fertil Steril 1986;45:620-4.

7 Guidice LC, Jacobs A, Pineda J, Bell GE, Lippman L. Serum levels of CA 125 in patients with endometriosis. Fertil Steril 1986;45:876-8.

8 Pittaway DE, Fayez JA. The use of CA 125 in the diagnosis and management of endometriosis. Fertil Steril 1986;46:791-5.

9 Patton PE, Field CS, Harms RW, Coulan CB. CA 125 levels in endometriosis. Fertil Steril 1986;45:770-3.

10 Hanisch FG, Uhlenbruck G, Dienst C, Stottrop M, Hippaunf E. CA 125 and CA 19.9: two cancer associated sialylsaccharide antigens on a mucus glycoprotein from human milk. Eur $J$ Biochem 1985;149:323-30.

11 O'Brien TJ, Hardin JW, Bannon GA, Norris JS, Quirk JG. CA 125 antigen in human amniotic fluid and foetal membranes. $\mathrm{Am} \mathrm{J}$ Obstet Gynecol 1986;155:50-5.

12 de Bruijin HWA, Calkoen-Carpay TVB, Jager S, Duk JM, Aalders JG, Flueren GJ. The tumour marker CA 125 is a common constituent of normal cervical mucus. Am J Obstet Gynecol 1986;154:1088-91. 
13 Nouwen EJ, Pollet DE, Eerderkens MW, Hendrix PG, Briers TW, DeBroe ME. Immunohistochemical localisation of placental alkaline phosphatase, carcinoembryonic antigen and cancer antigen CA 125 in normal and neoplastic human lung. Cancer Res 1986;46:866-76.

14 Halila H. Detection of ovarian cancer marker CA 125 in human seminal plasma. Tumour Biology 1985;6:207-12.

15 Masuho Y, Zalutsky M, Knapp RC, Bast RC, Jr. Interaction of monoclonal antibodies with cell surface antigens of human ovarian carcinomas. Cancer Res 1984;44:2813-9.

16 Matsuoka Y, Nakashima T, Endo K, et al. Recognition of ovarian cancer antigen CA 125 by murine monoclonal antibody produced by immunisation of lung cancer cells. Cancer Res 1987;47:6335-40.

17 Leoni F, Bast R, Canevari S, Soper J, Colnaghi M. Immunohistochemical characterisation and radioimmunometric detection of molecules shed by human ovarian cancer. Int J Cancer 1987; 40:592-7.

18 Kennedy SH, Soper NDW, Mojiminiyi OA, Shepstone BJ, Barlow DH. Immunoscintigraphy of ovarian endometriosis. A preliminary study. Br J Obstet Gynaeol 1988;95:693-7.

19 Laemmli UK. Cleavage of structural proteins during the assembly of the head of the bacteriophage T4. Nature (Lond) 1970;227:680-5.

20 Studier FW. Analysis of bacteriophage T7 early RNA and proteins on slab gels. J Mol Biol 1973;79:237-48.

21 Ward BG, Cruickshank DJ, Tucker DF, Love S. Independent expression in serum of three tumour-associated antigens: CA 125, placental alkaline phosphatase and HFMG-2 in ovarian carcinoma. Br J Obstet Gynaecol 1987;94:696-8.

22 Davis HM, Zurawski VR Jr, Bast RC Jr, Klug TL. Characterisation of the Ca 125 antigen associated with human epithelial ovarian carcinomas. Cancer Res 1986;46:6143-8.

Requests for reprints to: Dr O A Mojiminiyi, Department of Radiology, The Radcliffe Infirmary, Woodstock Road, Oxford OX2 6HE, England. 